\title{
CONSERVAÇÃO PÓS-COLHEITA DE GOIABAS 'KUMAGAI': EFEITO DO ESTÁDIO DE MATURAÇÃO E DA TEMPERATURA DE ARMAZENAMENTO
}

\author{
CRISTIANE MARIA ASCARI MORGADO², JOSÉ FERNANDO DURIGAN², \\ VALQUÍRIA GARCIA LOPES ${ }^{4}$, LEANDRA OLIVEIRA SANTOS
}

RESUMO - Este trabalho teve como objetivo estabelecer a importância do estádio de maturação e do uso da refrigeração na conservação de goiabas 'Kumagai'. Frutos "de vez" e maduros foram armazenados sob condição de ambiente $\left(21^{\circ} \mathrm{C}\right.$ e $85 \%$ UR) e a $10^{\circ} \mathrm{C}(85 \%$ UR) e avaliados periodicamente quanto à perda de massa fresca, aparência, podridões, coloração da casca, firmeza da polpa e teores de sólidos solúveis, acidez titulável, ácido ascórbico e polifenóis extraíveis totais, assim como da atividade antioxidante total. Goiabas "de vez", a $21^{\circ} \mathrm{C}$ e $85 \%$ UR, conservaram sua qualidade por seis dias, mas quando a $10^{\circ} \mathrm{C}$ e $85 \%$ UR, este período de conservação aumentou para 12 dias. Os frutos armazenados maduros conservaram-se por quatro dias sob condição ambiente, o qual foi ampliado com a refrigeração para 9 dias. Goiabas "de vez", armazenadas a $10^{\circ} \mathrm{C}$, apresentaram a maior vida útil, os maiores teores de sólidos solúveis e de acidez titulável. Também apresentaram aumento nos teores de polifenóis extraíveis totais, com aumento na atividade antioxidante total, e nos teores de ácido ascórbico.

Termos para indexação: Psidium guajava, armazenamento refrigerado, ponto de colheita.

\section{POSTHARVEST CONSERVATION OF 'KUMAGAI' GUAVAS IN TWO MATURATION STAGES UNDER TWO STORAGE TEMPERATURES}

\begin{abstract}
This work aimed to establish the importance of maturation stage and the use of refrigeration, for conservation of Kumagai guavas. Fruit in mature and ripe stage were stored under ambient condition $\left(21^{\circ} \mathrm{C} \mathrm{e} 85 \% \mathrm{RH}\right)$ and $10^{\circ} \mathrm{C}(85 \% \mathrm{UR})$ and periodic evaluated for weight loss, appearance, rotting evolution, color of peel, pulp firmness and soluble solids, titratable acidity, ascorbic acid and total extractable polyphenols content, and total antioxidant activity. Mature guavas at $21^{\circ} \mathrm{C}$ and $85 \% \mathrm{RH}$ preserved its quality for 6 days, but when at $10^{\circ} \mathrm{C}$ and $85 \% \mathrm{RH}$, this preservation period increased to 12 days. Fruit stored at ripe stage, were preserved for 4 days under ambient condition, which was enlarged with the refrigeration to 9 days. Mature guavas, stored at $10^{\circ} \mathrm{C}$, had the biggest shelf life and soluble solids and titratable acidity content. Also, showed increase in total extractable polyphenols content, with increasing values for total antioxidant activity, and ascorbic acid content.
\end{abstract}

Index terms: Psidium guajava, refrigeration storage, harvest point.

\footnotetext{
(Trabalho 271-09). Recebido em: 07-12-2009. Aceito para publicação em: 21-06-2010.

${ }^{2}$ Doutoranda em Produção Vegetal. UNESP/FCAV - Depto. de Tecnologia, CEP 14884- 900. cristianemorgado4@yahoo.com.br. Apoio financeiro: $\mathrm{CNPq}$

${ }^{3}$ Professor Titular. UNESP/FCAV - Departamento de Tecnologia, CEP 14884-900.jfduri@fcav.unesp.br

${ }^{4}$ Engenheira Agrônoma. valquiria.lopes@yahoo.com.br

${ }^{5}$ Doutoranda em Produção Vegetal. UNESP/FCAV - Departamento de Tecnologia, CEP 14884-900. leandraoli@yahoo.com.br
} 


\section{INTRODUÇÃO}

A goiabeira (Psidium guajava, L.) é originária da região tropical do continente americano, ou seja, do sul do México ao norte da América do Sul (MEDINA, 1988). O Estado de São Paulo é responsável por mais de $60 \%$ do volume nacional desta fruta, onde são cultivadas variedades de polpa branca, destinadas para consumo in natura e as de polpa vermelha com dupla aptidão, para consumo in natura e para indústria (MANTOVANI et al., 2004). No período de janeiro a julho de 2008, o volume de goiaba branca comercializado na Ceagesp foi, em média, de 119 toneladas por mês (AGRIANUAL, 2009).

A goiaba é uma excelente fruta para o consumo humano, dada sua riqueza em vitamina $C$, carotenoides, potássio, fibras, cálcio e ferro, além de possuir baixo conteúdo calórico e ótimo potencial antioxidante (MELTZER, 1998). Suas qualidades nutricionais fazem com que a goiaba tenha merecido atenção especial, tanto para o consumo in natura como para o desenvolvimento de novos produtos (DURIGAN et al., 2009).

$\mathrm{O}$ interesse dos consumidores e da comunidade científica em relação aos antioxidantes naturais tem aumentado, particularmente em relação àqueles encontrados em frutas e vegetais, tendo em vista que estudos farmacológicos demonstraram a associação entre o seu consumo e o baixo risco de doenças degenerativas (ORDÓÑEZ, 2005).

No Brasil, a produção de frutos com qualidade, objetivando a comercialização dos mesmos como produtos frescos, em mercados cada vez mais exigentes, tem sido destaque na fruticultura. Isto se deve às mudanças nos hábitos alimentares do brasileiro, o que leva à necessidade de se atentar para outros parâmetros de qualidade, como os antioxidantes, presentes em grande quantidade na goiaba (SOUZA, 2001).

O objetivo deste trabalho foi estabelecer a importância do estádio de maturação e do uso da refrigeração na conservação de goiabas 'Kumagai'.

\section{MATERIAL E MÉTODOS}

Goiabas 'Kumagai', que têm polpa branca, colhidas no município de Campinas-SP, a $262 \mathrm{~km}$ de distância de Jaboticabal, em 17-11-2008, foram armazenadas sob condição de ambiente controlado $\left(21 \pm 1^{\circ} \mathrm{C}\right.$ e $\left.85 \pm 5 \% \mathrm{UR}\right)$ e sob refrigeração $\left(10 \pm 1^{\circ} \mathrm{C}\right.$ e $85 \pm 5 \% \mathrm{UR})$. Os frutos foram colhidos em dois estádios de maturação, "de vez" e maduros, que correspondem aos estádios 3 e 5, respectivamente, descritos por Cavalini et al. (2006).

Essas goiabas foram imediatamente transpor- tadas até o laboratório, onde foram novamente selecionadas, lavadas com detergente neutro, enxaguadas com água potável e imersas em procloraz $\left(\right.$ Sportak $^{\mathbb{R}}$ - Bayer S.A) a 110 mL. $100 \mathrm{~L}^{-1}$, por 2 minutos, antes de serem secas ao ambiente.

As goiabas foram armazenadas em lotes com 65 unidades por tratamento, permitindo que amostras com 9 frutos ( 3 repetições com três frutos cada) fossem tomadas a cada 2 dias para os armazenados ao ambiente, e a cada 3 dias, para os a $10^{\circ} \mathrm{C}$. Durante o período de armazenamento, elas foram avaliadas quanto à perda de massa fresca, aparência, ocorrência de podridões, coloração da casca, resistência da polpa e teores de sólidos solúveis, acidez titulável, ácido ascórbico, polifenóis extraíveis totais e atividade antioxidante total.

A massa fresca foi quantificada, utilizando-se de pesagem em balança digital com capacidade para $2.000 \mathrm{~g}$ e precisão de $0,1 \mathrm{~g}$. Alterações na aparência foram avaliadas, conforme o indicado por Azzolini et al. (2004), segundo uma escala de pontos, onde: 1 = ótimo (fruto sem manchas e coloração típica); $2=$ bom (fruto com manchas em até $5 \%$ da casca e coloração típica); 3 = regular (fruto com manchas em 6-20\% da casca e coloração mais pálida); 4 = ruim (fruto com manchas em $21-40 \%$ da casca e coloração pálida), e $5=$ péssimo (fruto com manchas em mais de $41 \%$ da casca e sinais de senescência). A presença de podridões também foi determinada segundo uma escala de pontos, onde: $0=$ ausência; $1=$ indícios presença de patógenos com lesões de, no máximo, $1 \mathrm{~mm}$ de diâmetro; 2 = presença de podridões - presença de patógenos com lesões de, no mínimo, $2 \mathrm{~mm}$ de diâmetro (JACOMINO et al., 2003).

Os parâmetros de coloração da casca, luminosidade, ângulo de cor e cromaticidade, foram estabelecidos utilizando-se da metodologia indicada por Mattiuz e Durigan (2001). A firmeza da polpa foi avaliada com o uso de penetrômetro FT 327 com ponteira de $8 \mathrm{~mm}$, sendo os resultados expressos em Newtons.

O teor de sólidos solúveis foi doseado segundo o método 932.12, e o de acidez titulável, conforme o método 942.15 (AOAC, 1997). O teor de ácido ascórbico foi determinado segundo o sugerido por Rangana (1977), o de polifenóis extraíveis totais, segundo Rufino (2008).

A atividade antioxidante total foi estabelecida utilizando-se dos seguintes métodos, de acordo com Rufino (2008): captura do radical livre 2,2' - azinobis (3-etilbenzotiazolina-6-ácido sulfônico) (ABTS) e de redução do ferro (FRAP).

O ABTS é um método baseado na habilidade dos antioxidantes em capturar, a longo prazo, o 
cátion radical $\mathrm{ABTS}^{+}$. Os resultados são expressos em capacidade antioxidante equivalente a $1 \mathrm{mM}$ do trolox, que é um composto sintético, análogo à vitamina $E$, porém hidrossolúvel. É um método de elevada sensibilidade, prático e rápido, e através deste pode-se medir a atividade de compostos de natureza hidrofílica (KUSKOSKI et al., 2005).

O FRAP é um método baseado na capacidade de redução do ferro. Em meio ácido, o complexo férrico tripiridiltriazina é reduzido ao ferroso, mudando sua coloração para azul na presença de um antioxidante. Os resultados são expressos em capacidade antioxidante, equivalente a $1 \mathrm{mM}$ do $\mathrm{FeSO}_{4}$.

$\mathrm{O}$ experimento foi conduzido em delineamento inteiramente casualizado, com 3 repetições, com 3 frutos cada, e os resultados obtidos foram analisados através de regressão polinomial (GOMES, 1977).

\section{RESULTADOS E DISCUSSÃO}

As goiabas armazenadas a $21^{\circ} \mathrm{C}$ apresentaram maior intensidade de perda de massa fresca que as a $10^{\circ} \mathrm{C}$, e essa perda foi menor nos frutos maduros $(8,68 \%)$ do que nos "de vez" (Figura 1). Essa observação vem ao encontro do relatado por Oliveira (1996), que armazenou goiabas 'Kumagai' a $19,5-27^{\circ} \mathrm{C}$ e $59-76 \%$ UR e observou perda de $27,6 \%$ em 12 dias.

A casca tornou-se mais clara durante o armazenamento, o que é evidenciado pelo aumento nos valores da luminosidade, que nos frutos maduros e nos armazenados a $21^{\circ} \mathrm{C}$ foi mais acentuado (Figura 2), o que também foi relatado por Jacomino et al. (2000). A redução nos valores do ângulo de cor indica que a cor dos frutos maduros e dos armazenados a $21^{\circ} \mathrm{C}$ evoluiu mais rapidamente de verde para amarela, que nos "de vez" e nos armazenados a $10^{\circ} \mathrm{C}$ (Figura 2), o que foi semelhante ao encontrado por Cavalini (2004). A cromaticidade da casca dos frutos apresentou aumento nos valores de 32,33 para 45,93.

As mudanças na coloração refletem-se na aparência (Tabela 1), de forma que frutos "de vez", a $21^{\circ} \mathrm{C}$, conservaram boa aparência até o sexto dia, enquanto os maduros a conservaram por apenas 4 dias, o que também foi o observado por Cavalini (2004), ao armazenar goiabas 'Kumagai' a $25 \pm 2^{\circ} \mathrm{C}$ e $80-90 \%$ UR, colhidas em cinco estádios de maturação. Os frutos "de vez", a $10^{\circ} \mathrm{C}$, apresentaram boa aparência até o $12^{\circ}$ dia, enquanto os maduros a conservaram por 9 dias, reafirmando o relatado por Jacomino et al. (2000), que armazenaram goiabas 'Kumagai' sob quatro temperaturas $\left(2^{\circ} \mathrm{C} ; 8^{\circ} \mathrm{C} ; 10^{\circ} \mathrm{C}\right.$ e $\left.12^{\circ} \mathrm{C}\right)$ e 85 $90 \%$ UR, por 7; 14 e 21 dias, seguidos de mais 3 dias de comercialização simulada, a $25^{\circ} \mathrm{C}$.
A ocorrência de podridões foi retardada com o uso da refrigeração e do fungicida no início do experimento, pois os frutos armazenados a $21^{\circ} \mathrm{C}$ apresentaram indícios de podridões no sexto dia, enquanto, nos armazenados a $10^{\circ} \mathrm{C}$, as podridões apareceram, nos "de vez", aos 18 dias e, nos maduros, aos 15 dias de armazenamento (Tabela 1).

A firmeza da polpa dos frutos "de vez" reduziu-se com grande intensidade, enquanto, nos frutos maduros, ela foi mais lenta (Figura 1), como consequência do processo de amadurecimento (CHITARRA; CHITARRA, 2005). O armazenamento a $10^{\circ} \mathrm{C}$ reduziu a intensidade do amolecimento, como resultado da perda da integridade da parede celular (TUCKER, 1993).

Os teores de sólidos solúveis aumentaram e foram mais evidentes nos frutos "de vez" e nos maduros, mantidos a $21^{\circ} \mathrm{C}$ (Figura 3), o que também foi observado por Jacomino et al. (2000), que o atribuíram à normalidade do amadurecimento e da perda de massa, fatores que fazem com que aumente a concentração de açúcares na polpa.

Ocorreu a redução da acidez titulável da polpa nos frutos “de vez", armazenados a $21^{\circ} \mathrm{C}$, mas aumentou nos frutos sob condição refrigerada e nos maduros, armazenados ao ambiente (Figura 3), o que pode ser atribuído à intensidade do processo respiratório. Os valores variaram de $0,45 \mathrm{~g}$ ácido cítrico. $100 \mathrm{~g}^{-1}$ polpa a $0,65 \mathrm{~g}$ ácido cítrico. $100 \mathrm{~g}^{-1}$ polpa, o que está de acordo com o relatado por Gehardt et al. (1997), ou seja, que a acidez titulável de goiabas varia de 0,24 a $1,79 \mathrm{mg}$ de ácido cítrico. $100 \mathrm{~g} \mathrm{polpa}^{-1}$.

Durante o armazenamento, os frutos armazenados a $10^{\circ} \mathrm{C}$ apresentaram aumento nos teores de ácido ascórbico, enquanto nos armazenados a $21^{\circ} \mathrm{C}$ estes se mantiveram inalterados nos maduros ou também aumentaram nos "de vez", que após 8 dias apresentavam teor de 103,39 g de ácido ascórbico. $100 \mathrm{~g}$ de polpa $^{-1}$ (Figura 4). Jacomino et al. (2000) também observaram aumento no teor de ácido ascórbico em goiabas 'Kumagai', com os maiores valores nos frutos armazenados a $12^{\circ} \mathrm{C}$, evidenciando que o armazenamento próximo a $10^{\circ} \mathrm{C}$ proporciona um aumento nos teores de ácido ascórbico.

Os frutos maduros ou "de vez", armazenados em condição refrigerada ou não, apresentaram aumento nos teores de polifenóis extraíveis totais (PET) com o armazenamento, cujo teor médio foi de $73,60 \mathrm{mg} \cdot 100 \mathrm{~g}^{-1}$ ácido gálico (Figura 4). Este valor é inferior ao relatado por Thaipong et al. (2006), $344,90 \mathrm{mg} .100 \mathrm{~g}^{-1}$ ácido gálico, que estudaram extratos de goiaba cv. Allahabad Safeda que tem polpa branca. 
A atividade antioxidante total, determinada pelo método FRAP, aumentou nos frutos submetidos aos diferentes tratamentos, mas quando se utilizou o método ABTS, os frutos maduros, armazenados ao ambiente, mantiveram esta atividade inalterada durante o período de armazenamento (Figura 5). Os valores encontrados por Thaipong et al. (2006), em frutos de um genótipo de polpa branca, pelo método FRAP, foi de 37,90 $\mu \mathrm{mol}$ trolox. $\mathrm{g}^{-1}$ de massa fresca, o que é maior que os valores obtidos neste trabalho. A diferença entre os valores obtidos pelos métodos pode refletir a diferença relativa na habilidade dos compostos antioxidantes presentes nos extratos em reduzir o radical ABTS e o íon ferro em sistemas in vitro (THAIPONG et al., 2006).
Rufino (2008) avaliou a capacidade antioxidante de alguns frutos que pertencem à mesma família da goiaba, tais como camu-camu, uvaia e jambolão. Os frutos de camu-camu foram os que apresentaram maior capacidade antioxidante, com valor de 152,7 $\mu \mathrm{mol}$ trolox/g (ABTS) e 278,6 $\mu \mathrm{mol}$ sulfato ferroso/g (FRAP), o que foi superior ao encontrado neste trabalho. Frutos de jambolão e uvaia apresentaram capacidade antioxidante pelo método ABTS, de 29,7 $\mu \mathrm{mol}$ trolox/g e 18,0 $\mu \mathrm{mol}$ trolox/g, respectivamente, o que foi inferior ao encontrado para goiaba. Pelo método FRAP, os frutos de jambolão e uvaia também apresentaram valores menores do que os da goiaba.
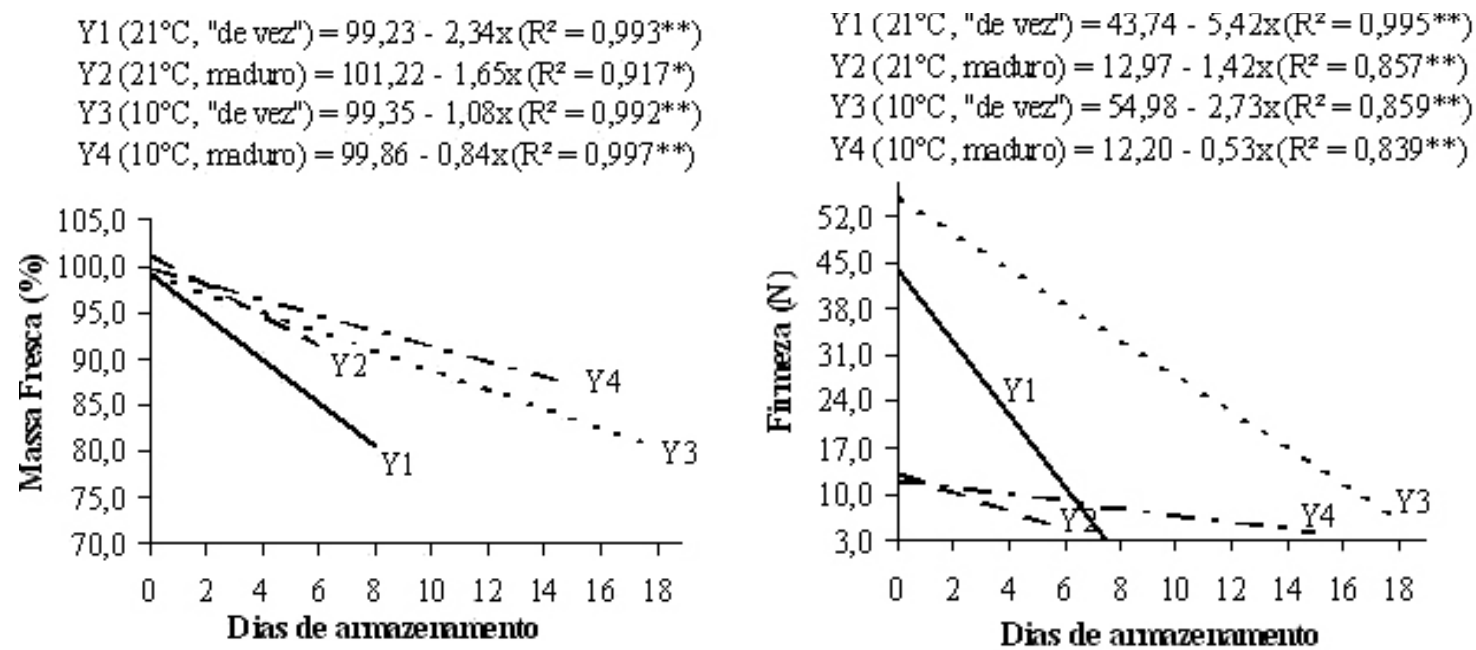

FIGURA 1 - Massa fresca e firmeza da polpa de goiabas 'Kumagai', armazenadas em dois estádios de maturação, sob diferentes temperaturas (Jaboticabal, 2008).

TABELA 1 - Evolução da aparência e de podridões de goiabas 'Kumagai', armazenadas em dois estádios de maturação, sob diferentes temperaturas (Jaboticabal, 2008).

\begin{tabular}{ccccc}
\hline $\begin{array}{c}\text { Tempo } \\
(\text { dia })\end{array}$ & \multicolumn{2}{c}{$21 \pm 1^{\circ} \mathrm{C}(85 \pm 5 \%$ UR $)$} & \multicolumn{2}{c}{$10 \pm 1^{\circ} \mathrm{C}(85 \pm 5 \% \mathrm{UR})$} \\
\hline 0 & $1(0)$ & $1(0)$ & $1(0)$ & Maduro \\
2 & $1(0)$ & $1(0)$ & - & $1(0)$ \\
3 & - & - & $1(0)$ & - \\
4 & $1(0)$ & $2(0)$ & - & $1(0)$ \\
6 & $2(1)$ & $4(1)$ & $1(0)$ & - \\
8 & $4(2)$ & - & - & - \\
9 & - & - & $1(0)$ & $2(0)$ \\
12 & - & - & $2(0)$ & $3(0)$ \\
15 & - & - & $3(0)$ & $5(2)$ \\
18 & - & - & $5(2)$ & - \\
\hline
\end{tabular}

Notas para a aparência - 1: ótimo; 2: bom; 3: regular; 4: ruim; 5: péssimo. Os valores entre parênteses indicam a ocorrência de podridões, onde 0: ausência; 1: indícios; 2: presença de podridões. 
$Y 1\left(21^{\circ} \mathrm{C}\right.$, "de vez" $)=0,20 \mathrm{x}^{2}-0,05 \mathrm{x}+61,83\left(\mathrm{R}^{2}=0,972^{*}\right)$

$\mathrm{Y} 2\left(21^{\circ} \mathrm{C}\right.$, maduro $)=62,63+1,94 \mathrm{x}\left(\mathrm{R}^{2}=0,982^{* *}\right)$

$\mathrm{Y} 3\left(10^{\circ} \mathrm{C}\right.$, "de ved $=0,05 \mathrm{x}^{2}-0,66 \mathrm{x}+61,60\left(\mathrm{R}^{2}=0,902^{* *}\right)$

$\mathrm{Y} 4\left(10^{\circ} \mathrm{C}\right.$, maduro $)=63,04+0,30 \mathrm{x}\left(\mathrm{R}^{2}=0,992 * *\right)$

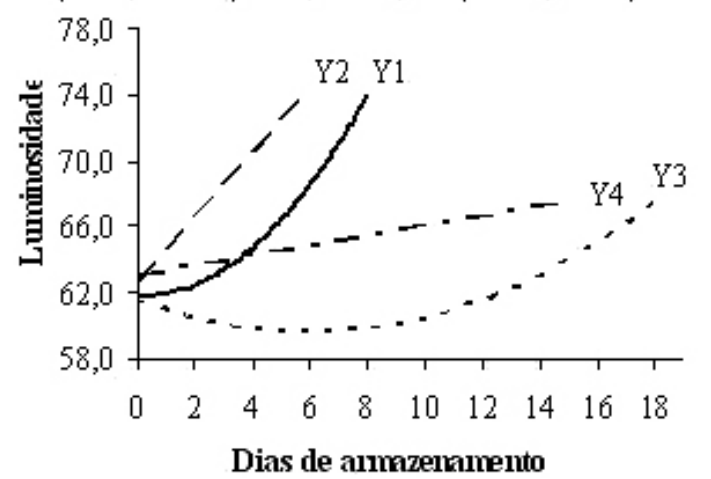

$\mathrm{Y} 1\left(21^{\circ} \mathrm{C}\right.$, "de vez" $)=0,39 \mathrm{x}^{2}+0,63 \mathrm{x}+121,35\left(\mathrm{R}^{2}=0,996^{* *}\right)$

$\mathrm{Y} 2\left(21^{\circ} \mathrm{C}\right.$, maduro $)=-0,47 \mathrm{x}^{2}-0,09 \mathrm{x}+118,9 \mathrm{Z}\left(\mathrm{R}^{2}=0,993^{* *}\right)$

$\mathrm{Y} 3\left(10^{\circ} \mathrm{C}\right.$, "de vez' $)=121,94-0,74 \mathrm{x}\left(\mathrm{R}^{2}=0,963^{* *}\right)$

$\mathrm{Y} 4\left(10^{\circ} \mathrm{C}\right.$, maduro $)=0,03 \mathrm{x}^{2}-1,22 \mathrm{x}+117,49\left(\mathrm{R}^{2}=0,995^{*}\right)$

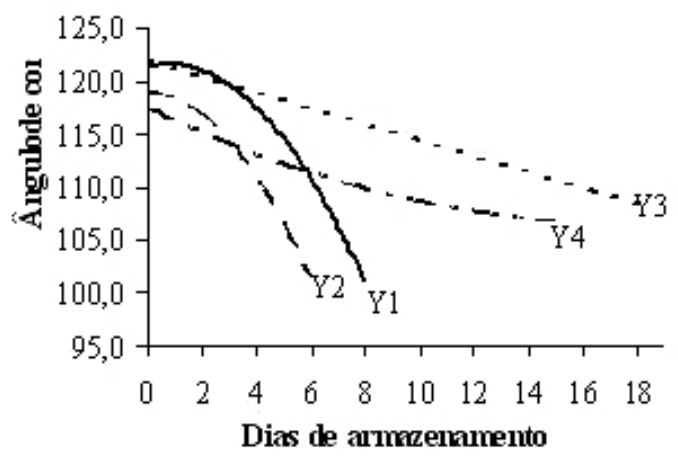

FIGURA 2 - Luminosidade e ângulo de cor da casca de goiabas 'Kumagai', armazenadas em dois estádios de maturação, sob diferentes temperaturas (Jaboticabal, 2008).

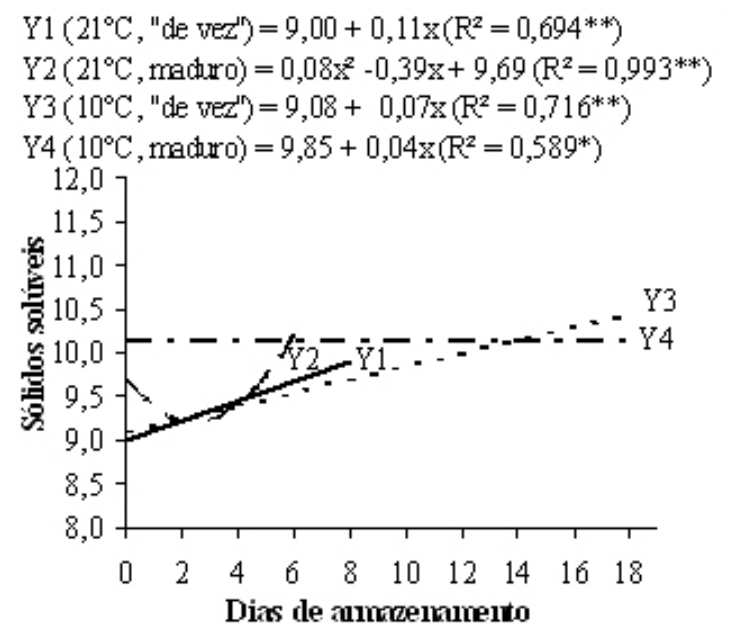

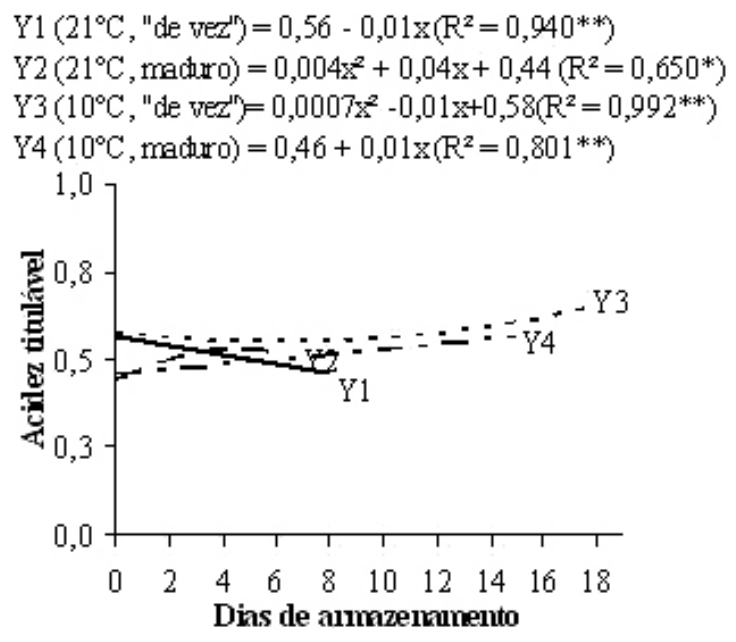

$\mathrm{Y} 1\left(21^{\circ} \mathrm{C}\right.$, "de vez" $)=0,56-0,01 \mathrm{x}\left(\mathrm{R}^{2}=0,940^{* *}\right)$

$\mathrm{Y} 2\left(21^{\circ} \mathrm{C}\right.$, maduro $)=0,004 \mathrm{x}^{2}+0,04 \mathrm{x}+0,44\left(\mathrm{R}^{2}=0,650^{*}\right)$

$Y\left(10 \mathrm{C}\right.$, de vez" $=0,0007 \mathrm{z}^{2}-0,01 \mathrm{x}+0,58\left(\mathrm{R}^{2}=0,992^{* *}\right)$

FIGURA 3 - Teores de sólidos solúveis ( ${ }^{\circ}$ Brix) e acidez titulável g ácido cítrico. $100 \mathrm{~g}^{-1}$ polpa) da polpa de goiabas 'Kumagai', armazenadas em dois estádios de maturação, sob diferentes temperaturas (Jaboticabal, 2008). 
$\mathrm{Y} 1\left(21^{\circ} \mathrm{C}\right.$, "de vez" $)=0,67 \mathrm{x}^{2}-7,22 \mathrm{x}^{2}+16,76 \mathrm{x}+89,47\left(\mathrm{R}^{2} \quad \mathrm{Y} 1\left(21^{\circ} \mathrm{C}\right.\right.$, "de vez" $)=2,38 \mathrm{x}+43,96\left(\mathrm{R}^{2}=0,983^{* *}\right)$

$\left.=0,571^{*}\right)$; Y $2\left(21^{\circ} \mathrm{C}\right.$, maduro $)=82,476(\mathrm{NS})$; Y3 $\left(10^{\circ} \mathrm{C}, \quad \mathrm{Y} 2\left(21^{\circ} \mathrm{C}\right.\right.$, maduro $)=0,94 \mathrm{x}^{2}-1,06 \mathrm{x}+45,91\left(\mathrm{R}^{2}=1,00^{* *}\right)$

"de vez" $)=0,02 \mathrm{x}^{2}-0,08 \mathrm{x}^{2}+0,02 \mathrm{x}+86,02\left(\mathrm{R}^{2}=0,812^{*}\right) ; \quad \mathrm{Y} 3\left(10^{\circ} \mathrm{C}\right.$, "de wez" $)=1,64 \mathrm{x}+42,34\left(\mathrm{R}^{2}=0,931^{* *}\right)$

$\mathrm{Y} 4\left(10^{\circ} \mathrm{C}\right.$, maduro $)=0,12 \mathrm{x}^{2}-2,84 \mathrm{x}^{2}+20,09 \mathrm{x}+84,06\left(\mathrm{R}^{2}=\mathrm{Y} 4\left(10^{\circ} \mathrm{C}\right.\right.$, maduro $)=3,38 \mathrm{x}+40,79\left(\mathrm{R}^{2}=0,953^{* *}\right)$
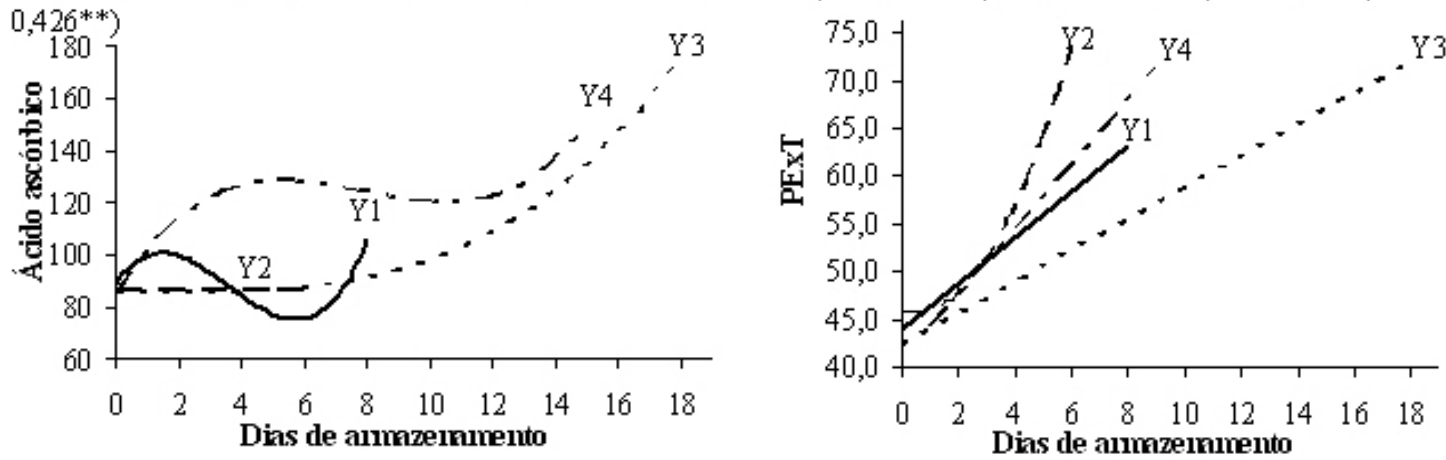

FIGURA 4 - Teores de ácido ascórbico (mg ácido ascórbico. $100 \mathrm{~g}^{-1}$ ) e polifenóis extraíveis totais (mg ácido gálico. $100 \mathrm{~g}^{-1}$ ) da polpa de goiabas 'Kumagai', armazenadas em dois estádios de maturação, sob diferentes temperaturas (Jaboticabal, 2008).
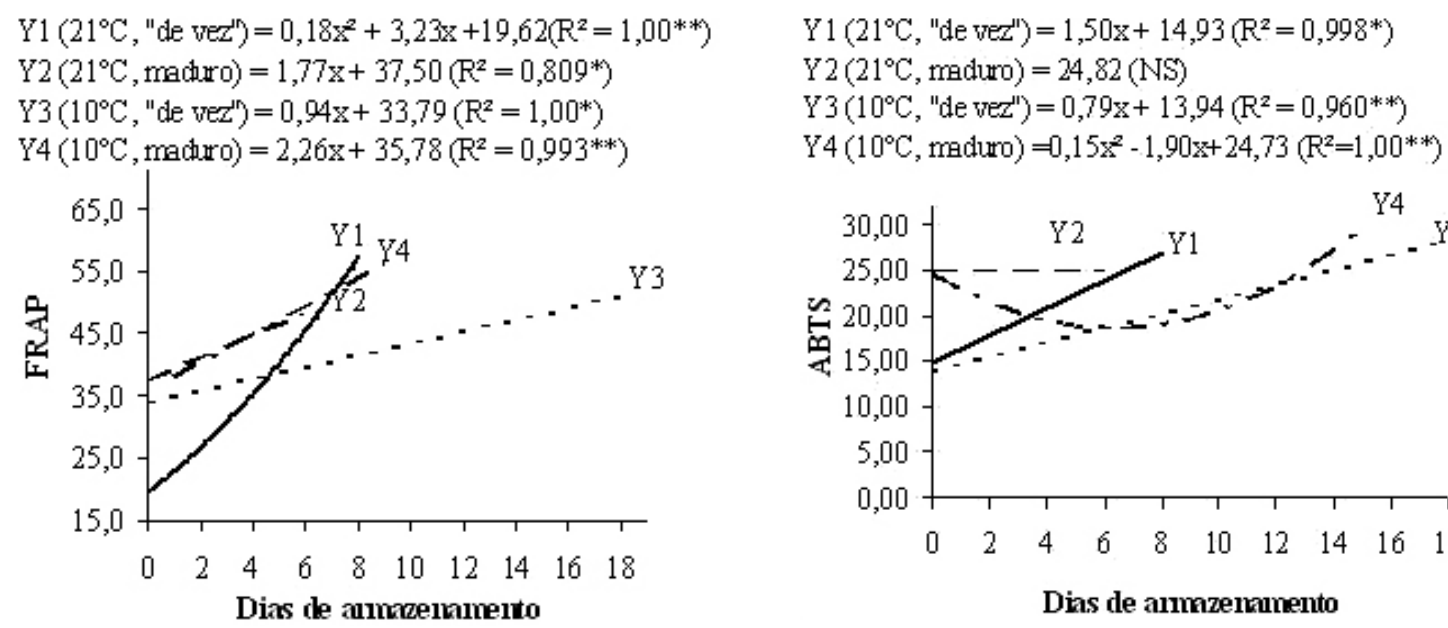

FIGURA 5 - Atividade antioxidante total determinada pelos métodos FRAP $\left(\mu \mathrm{M}\right.$ sulfato ferroso. $\left.\mathrm{g}^{-1}\right)$ e ABTS $\left(\mu \mathrm{M}\right.$ trolox. $\left.\mathrm{g}^{-1}\right)$ da polpa de goiabas 'Kumagai', armazenadas em dois estádios de maturação, sob diferentes temperaturas (Jaboticabal, 2008).

\section{CONCLUSÃO}

1-A vida útil dos frutos maduros, sob condição de ambiente $\left(21^{\circ} \mathrm{C}\right.$ e $\left.85 \% \mathrm{UR}\right)$, é de 4 dias. A $10^{\circ} \mathrm{C}(85 \% \mathrm{UR})$, as goiabas conservam-se por 9 dias. Goiabas “de vez", armazenadas em ambiente a $21^{\circ} \mathrm{C}$ (85\%UR), apresentam vida útil de 6 dias. Quando armazenadas a $10^{\circ} \mathrm{C}(85 \% \mathrm{UR})$, conservam-se por 12 dias.

2-A vida útil dos frutos, principalmente dos armazenados ao ambiente $\left(21^{\circ} \mathrm{C}\right.$ e $\left.85 \% \mathrm{UR}\right)$, é limitada pela intensidade de perda de massa fresca, mudanças na coloração da casca e podridões.
3-Goiabas "de vez", armazenadas a $10^{\circ} \mathrm{C}$, apresentam a maior vida útil, os maiores teores de sólidos solúveis e de acidez titulável. Também apresentam aumento nos teores de polifenóis extraíveis totais, com aumento na atividade antioxidante total, e nos teores de ácido ascórbico.

\section{AGRADECIMENTO} financeiro.
Os autores agradecem ao $\mathrm{CNPq}$, pelo apoio 


\section{REFERÊNCIAS}

AGRIANUAL 2008: anuário estatístico da agricultura brasileira. São Paulo: Instituto FNP, 2009. p.325.

AOAC. Official methods of analysis of the Association of Official Analytical Chemists International. 16. ed. Washington: Ed. Patrícia Cunniff, 1997. v.2, cap.37, p.932.12-942.15.

AZZOLINI, M.; JACOMINO, A. P.; SPOTO, M. H. F. Estádios de maturação e qualidade pós-colheita de goiabas 'Pedro Sato'. Revista Brasileira de Fruticultura, Jaboticabal, v.26, n.1, 2004.

CAVALINI, F.C. Índices de maturação, ponto de colheita e padrão respiratório de goiabas 'Kumagai' e 'Paluma'. 2004. 68 f. Dissertação (Mestrado em Ciências) - Escola Superior de Agricultura "Luiz de Queiroz", Universidade de São Paulo, Piracicaba, 2004.

CAVALINI, F.C.; JACOMINO, A.P.; LOCHOSKI, M.A.; KLUGE, R.A.; ORTEGA, E.M.M. Maturity indexes for 'Kumagai' and 'Paluma' guavas. Revista Brasileira de Fruticultura, Jaboticabal, v.28, n.2, p.176-179, 2006.

ChitARRA, M. I. F.; CHITARRA, A. B. Pós-colheita de frutos e hortaliças: fisiologia e manuseio. 2. ed. Lavras: Ed. UFLA, 2005. 785p.

DURIGAN, J.F.; MATTIUZ, B.H.; MORGADO, C.M.A. Pós-colheita e processamento mínimo de goiabas. In: NATALE, W.; ROZANE, D.E.; SOUZA, H.A. de; AMORIM, A.A. (Org.). Cultura da goiaba: do plantio à comercialização. Jaboticabal: FUNEP, 2009. v.2, p.429-470.

GERHARDT, L.B.A.; MANICA, L.; KIST, H.; SIELER, R.L. Características físico-químicas dos frutos de quatro cultivares e três clones de goiabeira em Porto Lucena-RS. Pesquisa Agropecuária Brasileira, Brasília, v.32, n.2, p.185-192, 1997.

GOMES, F. P. Curso de estatística experimental. Piracicaba: Nobel, 1977. 430p.
JACOMINO, A. P.; MARTINEZ OJEDA, R.; KLUGE, R. A. Conservação de goiabas tratadas com emulsões de cera de carnaúba. Revista Brasileira de Fruticultura, Jaboticabal, v.25, n.3, p.401-405, 2003.

JACOMINO, A. P.; SARANTÓPOULOS, C. D. I. de L.; SIGRIST, J. M. M.; KLUGE, R. A.; MINAMI, K. Armazenamento de goiabas 'Kumagai' sob diferentes temperaturas de refrigeração, Brazilian Journal of Food Technology, Campinas, v.1, n.3, p.165-169, 2000.

KUSKOSKI, E.M.; ASUERO, A.G.; TRONCOSO, A.M.; MANCINI-FILHO, J.; FETT, R. Aplicatíon de diversos métodos químicos para determinar actividad antioxidante en pulpa de frutos. Ciência e Tecnologia de Alimentos, Campinas, v.25, n.4, p.726-732, 2005.

MANTOVANI, J.R.; CORRÊA, M.C.M.; CRUZ, M.C.P.; FERREIRA, M.E.; NATALE, W. Uso fertilizante de resíduo da indústria processadora de goiabas. Revista Brasileira de Fruticultura, Jaboticabal, v.26, n.2, p.339-342, 2004.

MATTIUZ, B.H.; DURIGAN, J.F. Efeito de injúrias mecânicas na firmeza e coloração de goiabas das cultivares Paluma e Pedro Sato. Revista Brasileira de Fruticultura, Jaboticabal, v.23, n.2, p.277-281, 2001.

MEDINA, J.C. Cultura. In: INSTITUTO DE TECNOLOGIA DE ALIMENTOS. Goiaba. 2. ed. Campinas: ITAL, 1988. p.1-21.

MELTZER, W. Fantastic fruits. Nutrition Action Health Letter, 1998. Disponível em: <http:www. cspinet.org/nah/fantfruit.htm>. Acesso em: 30 out. 2009.

ORDÓÑEZ, J. A. Tecnologia de alimentos: componentes dos alimentos e processos. Porto Alegre: Artmed, 2005. p. 33-49.

OLIVEIRA, M.A. Utilização de película de fécula de mandioca como alternativa à cera comercial na conservação pós-colheita de frutos de goiaba (Psidium guajava). 1996. 73f. Dissertação (Mestrado em Ciências)- Escola Superior de Agricultura "Luiz de Queiroz", Universidade de São Paulo, Piracicaba, 1996. 
RANGANA, S. Manual of analysis fruit and vegetable products. New Delhi: McGraw-Hill, 1977. $634 p$.

RUFINO, M.S.M. Propriedades funcionais de frutas tropicais brasileiras não tradicionais. 2008. Tese (Doutorado em Agronomia) - Universidade Federal Rural do Semiárido, Mossoró, 2008.

SOUZA, R.A.M. de. Mercado para produtos minimamente processados. Informações Econômicas, São Paulo, v.31, n.3, p.7-18, 2001.
THAIPONG, K.; BOONPRAKOB, U.; CROSBY, K.; CISNEROS-ZEVALLOS, L.; BYRNE, D.H. Comparison of ABTS, DPPH, FRAP, and ORAC assays for estimating antioxidant activity from guava fruit extracts. Journal of Food Composition and Analysis, San Diego, v.19, p.669-675, 2006.

TUCKER, J.A. Introduction. In: SEYMOR, G.B.; TAYLOR, J.E.; TUCKER, G.A. Biochemestry of fruit ripening. London: Chapmal \& Hall, 1993. cap.1, p.2-51. 